\title{
The art of living in prison: A pragmatist aesthetic approach to participatory drama with women prisoners
}

\section{ABSTRACT}

Across the fields of applied theatre and prison theatre, there appears to be little analysis of aesthetics and aesthetic engagement for participants in prison-based participatory practices. This article presents a pragmatist aesthetic frame that I developed to analyse the experience of a drama programme I ran in a women's prison. This frame evolved alongside the practice, drawing largely from John Dewey's (1934) Art as Experience and a selection of contemporary scholars who, influenced by Dewey, work in the areas of aesthetics, ethics and education - most notably Richard Shusterman (2000, 2008) and David Granger (2006). I also incorporated narrative within this frame as an interpretive and expressive structure for experience, and a key element within my applied theatre practice. I began to conceive aesthetics in terms of an 'art of living', identifying a 'poetics of renewal' that informed the selfand world-creation of participants in the drama. I share this theoretical framework as a possible way to integrate the instrumental and the aesthetic in applied theatre theory and practice, specifically in a prison context.

\section{KEYWORDS}

aesthetics applied theatre participatory drama prison theatre somaesthetics women prisoners 


\section{INTRODUCTION}

A recent surge of interest in applied theatre aesthetics has invited us to consider the ways in which politics, participation and process inform our understanding of the aesthetic in this wide and often-contested field. Although scholars in the field of drama in education have consistently explored the aesthetic dimensions of how drama engages and educates, Haseman and Winston (2010) suggest that the broader field of applied theatre scholarship has previously neglected the aesthetic, being more focused on the instrumental aspects of the work. They argue that this may be due partly to classicist Kantian versions of aesthetics not reflecting the embodied, participatory and democratic practices of applied theatre and its 'gritty' contexts (2010: 465). Aesthetic theory has likewise been limited in prison theatre scholarship, which appears to reflect an enduring focus on its instrumentalist agenda, in conversation with performance theory, cultural theory and most recently cultural criminology. It has been observed that in prison-based practice, the need to secure funding and gain credibility in criminal justice settings often contributes to the perpetuation of an instrumental focus. In much of the prison theatre literature, it is possible to get a glimpse of, and in some cases considerable detail about, the aesthetic approaches or performance products created; however, as White (2015: 5) notes with regard to applied theatre, the term 'aesthetic', when it is actually used, 'Stands for a broad category of the artistic or the art-like', rather than a rigorous approach to practice or epistemology.

Aside from Bottoms' (2010) analysis of Geese Theatre Company's performance and workshop programme Journeywoman, I have found very little, if any, exploration of aesthetic experience and engagement for the participants and audiences involved in prison-based theatre practices. Here I hope to address this, and respond to the tension that exists between aesthetics and instrumentalism in the work by presenting a pragmatist aesthetic frame that I developed to analyse the experience of a drama programme I ran in a women's prison. This frame evolved alongside the practice, drawing largely from John Dewey's (1934) Art as Experience and a selection of contemporary scholars who, influenced by Dewey, work in the areas of aesthetics, ethics and education, most notably Richard Shusterman $(2000,2008)$ and David Granger (2006). I also incorporated narrative theory into the frame, informed by Jerome Bruner (1986, 1990) along with a selection of others who have followed, including Theodore Sarbin (1998). I integrated this pragmatist aesthetic view with applied theatre theory in its broadest sense, embracing prison theatre, drama in education, therapeutic drama and community-based theatre theories as being reflective of my own hybrid practice over the past 20 years. By integrating these ideas with the unfolding experience of the programme, I began to conceive aesthetics in terms of an 'art of living', identifying a 'poetics of renewal' that existed within the drama process. These concepts were useful to me in understanding the intermingling of experiences and narratives that occurred both within and outside the frame of the drama. Through this article, I seek to share this framework as a possible way to integrate the instrumental and the aesthetic in applied theatre theory and practice, specifically in a prison context.

\section{BACKGROUND}

In 2011, I delivered a drama programme for women prisoners at Brisbane Women's Correctional Centre (BWCC) in Queensland, Australia that I called Living Stories, using a range of different approaches including improvisation, 
process drama, image theatre and devising. Having previously worked for some years with Geese Theatre Company in the United Kingdom, I was interested in the potential for my practice in prisons to move away from an explicitly rehabilitative agenda. This interest was spurred on by Hughes' (2005: 13) call for the prison theatre field to develop 'its own body of theory from which arts-specific models of change can be identified'. My hope was to explore the ameliorative potentials of drama for prisoner participants through the art form itself rather than importing models of change from offender rehabilitation theory. This, of course, raised the same enduring tensions for me as a practitioner. I was still essentially working as an instrument of the institution to progress its offender rehabilitation agenda, and I was still entertaining the problematic notions of 'change' or 'transformation' in the context of an interventionist programme. But I also hoped to address this tension by interrogating notions of change, correction or rehabilitation through the women's aesthetic engagement in the drama and in ways that would privilege their own versions of these concepts rather than those that were being imposed by the institution or the state. In a sense, I was attempting to navigate my way from seeing the participants as offenders to seeing them as potential artists and cultural agents.

\section{THE PRACTICE AND RESEARCH}

My practice in Living Stories was essentially a range of brief experiments with approaches such as image theatre, text-based work, improvisation games, drama skills development and process drama, finally finishing with a group devised performance. This occurred as I searched simultaneously for my own renewed voice as a practitioner and the drama approaches that I felt would respond best to the context. Participation was voluntary, and I ran the programme over 23 two-hour sessions with a group that fluctuated between five and nine participants. Within this experimentation, it was difficult to facilitate frequent and sustained periods of aesthetic engagement for the participants. The potential for such engagement was also thwarted by the operational struggles of getting the women cleared by the authorities to attend, and cleared to stay in the room for the duration of our two-hour sessions; and the highly mobile nature of the prison population in BWCC. While certain moments and exercises did yield interesting insights in terms of aesthetic experience, moments of deeper aesthetic engagement appeared to be few and fleeting. As such, Living Stories could be described as a 'good enough drama' (Rasmussen 2010), a phenomenon that appears on the face of it difficult to analyse aesthetically, but that I would suggest exists quite commonly in applied theatre and prison theatre. While we often strive for aesthetically powerful work in terms of both process and product, it can be difficult to achieve. I developed the analytical frame described here gradually as I worked through data consisting of my own reflections, as well as voice-recorded workshop sessions and interviews with the participants. The purpose of this article is not to present a comprehensive set of discoveries or findings, but rather to introduce this theoretical frame and then briefly touch on some of the ways in which it was applied to Living Stories.

\section{THE AESTHETIC}

The use of the term 'aesthetic' commonly incites confusion over whether it refers to art alone, or can be applied to other objects and experiences; whether 
it refers to things of beauty and experiences of pleasure, or can equally be applied to ugliness and pain; whether it has value, or exists for its own sake; whether its value can be measured objectively, or only subjectively; whether it is an integral, vital form of human knowledge, or an added extra - a cherry on top. Shusterman (2008: 217-18) observes that aesthetic experience is also a difficult term to define, with the concept of experience having its own history and nuances within philosophy. As a result, contemporary debates in aesthetics cover such questions as whether or not everyday experiences such as sex, sport and enjoying a good meal can be aesthetic in nature. Winston (2010) provides a useful summary of aesthetics since Kant, suggesting that Kantian aesthetics was very much a product of its age, generated by rational, logical reasoning and privileging the mind over the body. He suggests that echoes of this vision of the aesthetic can still be felt strongly today. However, aesthetic theorists such as Johnson (2007) and Shusterman (2008) have built on the work of Dewey, as well as others like Emerson, Merleau-Ponty and Thoreau, in repairing this mind-body split and conceiving the entire human body as both expressive instrument and receptive locus of aesthetic experience. I see this turn towards embodiment in aesthetics as being vital in applied theatre, a democratic process in which participants are similarly empowered as both makers and perceivers of the work: 'percipients' or 'spectactors'. This view of the aesthetic has perhaps been articulated best over the years within the field of drama and theatre in education, where the emphasis is placed upon aesthetic engagement as integral to learning for children and young people. Prendergast and Saxton (2009) describe the aesthetic in applied theatre as being based on nurturing aesthetic experience in participants through the process; recognizing the aesthetic for integral audiences; the art of making the ordinary extraordinary; and the pursuit of authenticity - that is, harnessing the power in community stories and raw, sometimes unskilled performances. Although White (2015: 11) remains sceptical that there exists a singular applied theatre aesthetic, the work collected in his recent volume reflects a similar view.

\section{BUILDING A PRAGMATIST AESTHETIC FRAME}

In applied theatre scholarship, there is a sense of conviction that a distinction between 'applied' and 'pure' theatre is not useful or relevant; that aesthetic engagement is an embodied, democratic, culturally situated process; and that its instrumentalism is inherently bound together with its aesthetic power. My focus on the aesthetic in this work covers both process and product: the aesthetic engagement of participants within the processes of play, improvisation and devising, and the performance products that were created from moment to moment and in the final showing. It also includes the many moments and conversations that occurred outside and around the dramatic frame. These features are strongly reflected in John Dewey's only treatise on aesthetics, Art as Experience (1934), in which he sets out an embodied, experiential aesthetic theory that integrates art and life. He proposes that experience in all of life has potentially aesthetic qualities, and that aesthetic experience in both life and art is a rhythmic process of interactive, culturally determined meaning-making that integrates cognition, imagination, emotion and action as they move towards qualitative unity. Yet experience on its own does not necessarily move us towards the aesthetic. To do this, it must be an experience. Dewey distinguishes between 'art-centred' and 
'ordinary' aesthetic experiences, but suggests that for something to be characterized as an experience, it must 'run its course to fulfilment' (1934: 36). Such experiences, Dewey suggests, do not merely end, but are 'consummatory': they are rounded out to become suffused with meaning. He illustrates this using the metaphor of a river and a pond, pointing to the hermeneutic quality of an experience:

A river, as distinct from a pond, flows. But its flow gives definiteness and interest to its successive portions greater than exist in the homogenous portions of a pond. In an experience, flow is from something to something. As one part leads into another and as one part carries on what went before, each gains distinctness in itself. The enduring whole is diversified by successive phases that are emphases of its varied colours.

Dewey's version of the aesthetic is not relegated to being some objective, distant, rarefied ideal, but engages all human beings in active alive participation - of doing and undergoing. It is, Johnson (2007: xi) suggests, concerned with 'the bodily depths of human meaning-making through our visceral connection to our world'.

A small number of drama education practitioners and theorists have either overtly acknowledged Dewey in conceptualizing their work, or else their work implicitly reflects a Deweyan concept of aesthetic experience (e.g. O'Neill 1995). White suggests that Thompson's (2009) emphasis on the affective experience over the effects of applied theatre is reminiscent of Dewey's aesthetics (2015: 9). Dewey's emphasis on both process and product in aesthetic experience has informed Taylor and Warner's (2006: 61) analysis of 'dynamic form' in O'Neill's process drama, where they liken it to Dewey's concept of an experience. The notion of dynamic form can equally be seen reflected in Johnston's (1998) 'six polarities' of community drama practice, which indicate a constantly shifting dynamic between binaries such as 'surface and depth', 'centre and edge' and 'the simple and the complex'. Describing a community-based applied theatre project, Rasmussen and Gürgens (2006) offer useful distinction between the 'art work' (process) and the 'artwork' (product), emphasizing the aesthetic that exists in both. White (2015: 46) similarly suggests an 'aesthetics of process' in which the practices and experiences of participation should be valued as art works. A programme such as Living Stories can therefore be seen in Deweyan terms as an experience, within which there may have been numerous objective art works created; and numerous experiences that were art-centred, ordinary and sometimes extraordinary. These 'varied colours' flowed together in terms of understanding and making meaning, forming part of a larger, integrated whole.

\section{INCORPORATING NARRATIVE INTO THE FRAME}

A vital element of my theoretical approach was the inclusion of narrative as an interpretive and expressive structure for understanding experience in Living Stories. Following the work of Jerome Bruner $(1986,1990)$ and Theodore Sarbin (2005), narrative can be seen as the ice that momentarily freezes Dewey's river of experience into an organizing structure, with the knowledge that the ice will then change the character of its flow. Clandinin 
and Connelly (2000: 50) acknowledge the connection by simply stating, 'Why narrative? ... Because experience.' Ricoeur (1984: 56) claims that, 'There is no structural analysis of narrative that does not borrow from an explicit or an implicit phenomenology of "doing something"'. Turner's concept of 'social dramas' appeared in Mitchell's seminal collection On Narrative (1981), in which he traces the linguistic roots of the word narrative to define it as 'knowledge emerging from action' or 'experiential knowledge'. Peterson and Langellier (2007: 206) propose that there should be a 'performative turn' to narrative theory that explores 'the behaviours, habits, practices, and institutions which enact, execute, or do narrative'. Nicholson (2005: 63) presents a relatively brief and rare description of the applied theatre field informed by narrative theory, acknowledging drama as a 'narrative art'. In a participatory drama project, we 'do narrative' in the meta-performative sense that Petersen and Langellier describe, and where we perform narratives through a range of dramatic forms and structures. In both cases, narratives are experienced and expressed within and through the body.

\section{THE ART OF LIVING IN PRISON}

Throughout his treatise, Dewey returns to the idea that experience is a fundamental rhythmic interaction between the self and the world that has ethical implications:

To gain an integrated individuality, each of us needs to cultivate his own garden. But there is no fence about this garden: it is no sharply markedoff enclosure. Our garden is the world, in the angle at which it touches our own manner of being ... We, who are also parts of the moving present, create ourselves as we create an unknown future.

(Dewey 1929, cited in Granger 2006: 203)

This statement positions Dewey's (1934) aesthetics as an art of living where, as Shusterman (2000: 18) suggests, the pragmatic goal of aesthetic theory should be to enrich the human experience and help us to lead more fulfilling lives: to 'cultivate our gardens'. He proposes somaesthetics as a theory that places the body at the centre of this process. The sense of unity - the philosophy of living aesthetically and the position of the aesthetic at the centre of everyday ordinary experience and ethical conduct - is, as some have recognized, closely aligned to Eastern philosophies such as Confucianism, Buddhism and Taoism (Shusterman 2000). In other words, the traditional split between the aesthetic and the everyday or social dimensions of human experience could be seen as a largely Western construct.

I believe that onceiving of an art of living in the context of prison theatre offers some depth and dimension to the frequently professed but little analysed humanizing qualities of the work. Here, narrative and aesthetic engagement and experience are informed by their situation within an oftenalienating institutional space. Kershaw (2004) and McAvinchey (2011) begin to discuss prison theatre and performance in these terms, where the tensions between the institutional context and the moments of freedom, beauty or transcendence that occur in the drama space become integral to the aesthetic. In commenting on the institutionalization of modern society, Dewey (1934: 21) observes, 'Prestige goes to those who use their minds without participation of the body and who act vicariously through control of the bodies 
and labour of others.' Alexander (1998: 13) argues that in Dewey's view, 'Art, when placed in its natural, ecological context, points the way for the liberation of the sensuous human body from its institutionalised alienation.' Prisoners are largely prevented from having 'active and alert commerce with the world' (Dewey 1934: 19), an idea that Foucault (1991) explores through the concept of 'docile bodies' in his seminal analysis of society's development towards modern forms of imprisonment. While Foucault's work has formed the basis for considerable performative analysis of (especially women) prisoners' bodies within the carceral space (e.g. Walsh 2014), I believe there is also potential in exploring the unique qualities of embodied narrative-aesthetic experience and engagement for drama participants in what Jewkes (2012) describes as a largely 'an-aesthetic' institutional space.

\section{AN EMBODIED POETICS OF RENEWAL}

In conceiving an embodied poetics of renewal, I have embraced the work of Granger $(2001,2006)$, who builds on Dewey in his exploration of the concepts of personal and cultural renewal in aesthetics and aesthetic education. Granger acknowledges the influence of Emerson and Wordsworth on Dewey in seeing renewal as an ever-expanding horizon that grows through the 'ongoing process of marriage and remarriage with the world' (2006: 208-09). He describes a 'poetics of self-creation' that echoes Sarbin's (1997) 'poetics of identity'. In Sarbin's view, the use of the term 'poetics' implies that the self is created through a process of 'making, fashioning, and configuring in the context of telling stories' (1998: 297), echoing Bruner's (1990) view of self-narrative. Granger (2001: 109) argues that, 'Self-making is only an initial step along the eventual path to self-remaking, entailing reciprocating activity within and beyond the habitual self.' This pragmatist view aligns with postmodern, performative and constructivist images of the self as not a fixed essential entity, but rather a fluid, evolving and culturally dependent set of behaviours, habits, beliefs and experiences. As Granger (2006: 3) suggests, 'Dewey's aesthetics actively nurtures ... the human Eros: the native impulse to live life with an ever-expanding sense of meaning and value.' Garrison (1997: 147) explains that this nurturing of Eros is a far more social proposition than the more narcissistic versions of self-creation and self-actualization that are characteristic of much postmodern thought: 'The idea of social self-creation involves learning to play creatively with others, especially those who are different from us.' The processes of personal and cultural renewal are therefore seen as embodied, interdependent processes of self- and world-creation. These concepts are reflected in the idea that participatory drama can involve the creation of 'possible selves' (O'Neill 1995: 79) and 'performed utopias' (Prendergast, 2011), which are recognized as inherently ethical processes.

The narrative and aesthetic theory on which I have drawn here also recognizes renewal as being a process that is not necessarily a relentless march towards beauty and goodness. Both Shusterman and Granger acknowledge that Dewey's version of unity can embrace the 'fragmented or discordant' (Shusterman 2008: 87). Granger (2006: 132) suggests that, 'Experiences involving some degree of pain, loss, or even the conventionally "ugly" can have a palpable aesthetic quality insofar as they heighten our appreciation for the intrinsic meaning and value of those things that make up our everyday lifeworlds.' Indeed, Dewey moves through five chapters 
of his treatise before addressing the notion of beauty, which he describes as 'an obstructive term' that should not be used to describe the aesthetic quality of experience (1934: 135). Dewey suggests that the passage between disturbance and harmony provides us with the moment of 'intensest life' (1934: 17). Stoller (2013: 29) believes that disharmony and dis/integration are equally important aesthetic categories as harmony and beauty in teaching and learning. In his description of an 'aesthetics of participation', White (2015: 45) suggests that, 'There will be moments of beauty, and other typically aesthetic experiences in these processes, but the difficulties and conflicts are important too, often being when the most significant learning or personal change happens.' Bharucha (cited in Mackey and Stuart Fisher 2011) encourages us to embrace the 'perverse beauty' within the aesthetics of applied theatre in order to move it away from a simplistic discourse of truth and goodness. In applied theatre, personal and cultural renewal and ethical participation can therefore be seen as dependent upon engaging with every aspect of human experience, including the tensions brought about by ugliness, conflict and failure.

\section{POETICS OF RENEWAL IN THE PRISON CONTEXT}

In Sarbin's (2005) terms, the prison as a 'stage for the enactment of human dramas' will invariably influence the kinds of dramas that are created there. In analysing the 'an-aesthetics' of prison architecture, Jewkes (2012: 25) describes contemporary prison design as a 'technology of disenchantment', where the majority of such spaces are 'bland and grindingly dull' (2012: 32). Foucault (1986: 24) recognizes the prison as a 'heterotopia' - a counter-site where real society is 'simultaneously represented, contested and inverted'. He further notes the 'introduction of the "biographical"' into the history of penology, describing modern penitentiaries as 'a sort of artificial and coercive theatre' in which the prisoner's life and biography 'will be examined from top to bottom' in order to find causality for their criminality (1991: 251-52). In the contemporary prison bureaucracy, prisoners must repeat their personal narratives in assessment meetings, parole hearings and other administrative procedures in order to demonstrate their psychological needs, the presence of contrition and the potential for recidivism. Progressive rehabilitation theorist Shadd Maruna (2001) has embraced the notion of narrative in his proposal for meaningfully addressing desistance from crime, focusing on how ex-offenders construct their own narratives of 'making good'. But by its very nature and spatial structure, prison has the potential to perpetuate embodied adversarial narratives and roles. Easteal (2001) describes the 'dysfunctional culture' within Australian women's prisons, where women are encouraged by the institution to adopt the survival strategies that they have learned growing up in abusive and dysfunctional homes: 'Don't talk, don't trust and don't feel.' Geese Theatre Company's Fragment Masks represent a taxonomy of eight coping behaviours that are found in the over-arching mask of survival within the prison environment and in other areas of offenders' lives (Baim et al. 2002: 184-85). One of these masks, the 'Brick Wall', directly echoes Easteal's triad of negative coping behaviours. These ideas demonstrate for me the interaction between the carceral space, the culture inside, and the kinds of narratives, roles and selves that repeatedly are created there. Renewal is dependent upon understanding and working within the tensions that these poetic constructions bring about. 


\section{POETICS OF RENEWAL IN LIVING STORIES}

Throughout the course of the Living Stories programme, several of the women participants articulated a desire for personal renewal: to live better lives, to become better people and to be seen as better people by others. I discovered early on that this was a subjective endeavour that varied from woman to woman, and quite often involved rejecting institutional versions of these ideals. Almost without exception, they regarded the institutional rehabilitation programmes offered at BWCC with contempt: when I asked one woman directly about the notion of rehabilitation, she replied, 'Yeah, that's their word, but don't ask us to spell it.'

In terms of the drama programme, the women did not embrace the idea of performance based on personal narrative or testimony as a pathway towards renewal. During an early conversation that followed the drama game FourMinute Life Story (a community-building and performance exercise where, in pairs, participants exchange their life stories in four minutes and are then asked to perform their partner's life story using only movement), two of the women said that they were sick of telling their life stories to all the various state authorities, with one further adding that she was sick of having to 'live by' her story. From then on, this prompted me to avoid explicitly using personal testimony or narrative as the basis for our devising.

Yet despite this, many of the women continued to share their personal stories with me in moments outside the drama. I therefore became interested in how the drama interacted with the events that were happening outside it, how fictional and factual narratives and roles merged together both formally and informally within the workshop space, and how these might inform a poetics of renewal for the group as a whole, and the individuals within it. Despite a common conception of the drama workshop as a space of safety and freedom inside the punitive machinery of the prison, Living Stories did not always feel like a fenced-off sanctuary, but rather had boundaries that were permeable and sometimes risky; these tensions also informed the kinds of personal and cultural renewal that were possible there.

The coping mechanisms described by Easteal (2001) and Geese Theatre Company above were certainly present and visible within Living Stories. In discussing what benefits the drama might have for participants, one woman (whom I will call Gwen) described how the drama could bring out something other than the 'bound-up prison person'. When I asked her to clarify what this bound-up prison person was, she described someone being careful about what they said and did, whereas in the drama workshop, she suggested, people could relax. I became interested in this idea of being 'bound-up', which was interpreted in different ways throughout the programme. One woman described the fear she felt playing improvisation games in the first drama session: 'You're so used to boxing everything here.' Another said it was a case of being 'reserved' where things go 'in one ear and out the other' and a third followed by saying that it was 'running on bare minimum'. The same woman later said that she often felt like a robot. These images of brick walls, robots, boxes, binding and bare minimum have strong somatic connotations. Gwen's image of the bound-up prison person therefore became critical for me in how I conceived a poetics of renewal for the participants in this context.

By integrating Gwen's image of the bound-up prison person with Shusterman's (2011) somaesthetics, I saw renewal in Living Stories as 
inextricably tied to a sense of 'unbinding'. Different women in the group demonstrated different forms of binding, depending on their own particular life circumstances and survival strategies. Somatic binding was visible in the roles that they played both inside and outside the drama, and these were bound up in the sometimes-painful narratives that perpetuated them. I conceived these repeated roles and narratives using Granger's (2010: 72) interpretation of Dewey's 'habits' - what he also describes as 'arts' - which we develop as embodied responses to our environment, and which appear as 'expressions of culture rooted in the lived body and mediated by social interaction'. I found that the women habitually storied their life in prison as either an adversarial 'game', or else a life on hold - what one woman called 'groundhog day'. The bound-up prison person was a key role that the women manifested in different ways as they negotiated their way through these narratives. Both Shusterman and Granger explore the idea that renewal is an expanding process that relies on the rhythm between habit and innovation, which for Shusterman occurs via spontaneity. Stagnant, negative or destructive habits, he suggests, can be ameliorated through embodied (or somaesthetic) practices. I therefore saw renewal in Living Stories as being dependent upon the participants having an opportunity to exercise their habitual roles and narratives within the drama process, and in some cases reconfigure these through somaesthetic engagement and spontaneity, towards innovation. Innovation in Living Stories was dependent on the participants having a sense of openness to possibility or risk, of letting go, but with habit acting as a kind of touchstone to help gauge the risk, and anchor the meaning and value of their expansion into new horizons. It was therefore not always as simple as creating new narratives, experimenting with new roles, trying something new or showing a new (better) side of oneself. There was a constant sense of necessary tension that underpinned the embodied poetics of self- and worldcreation in this context; sometimes habitual roles and narratives would be reinforced within the drama process, and it did not always result in unbinding or renewal.

\section{CONCLUSION}

By exploring the notion of 'unbinding', I have begun to see the potential applications of Shusterman's somaesthetics to prison-based participatory drama. With the enactment of possible selves and possible worlds, and the presence of improvisation and spontaneity, participatory drama can be seen as a potentially somaesthetic practice. The drama process integrates habit with innovation in an absorbing somatic, and potentially somaesthetic, sense that can ultimately reconfigure habits and move them towards renewal. This might extend the discussion that has already begun with regard to somaesthetics and art forms such as dance, body art and contemporary performance practices in which the body itself is the instrument for expression (e.g. Arnold 2005). White (2015: 77) argues that, due to its focus on individual well-being over social change, Shusterman's work does not 'map across' to applied theatre entirely. I would suggest, however, that Shusterman's embrace of Eastern philosophies such as Buddhism, and the work of Dewey, de Beauvoir, Bourdieu and Foucault certainly signal the social and cultural implications of somaesthetic theory and practice. While my study focused more on personal than cultural renewal, I see potential to explore how both might interact with each other in a prison context. Part of this might involve turning the analysis 
inwards as a practitioner-researcher, exploring how my own embodied poetics of self-creation interacts with that of the participants, or engaging with prison staff and the wider culture of criminal justice in a similar way. Finally, despite its emphasis on the soma as the medium of expression, Shusterman's theory so far provides little exploration of the subjective nature of somaesthetic experience, or what it might mean to experience somaesthetic engagement. Study in this area might deepen our understanding of how to articulate the embodied complexity of experience within participatory drama and how this can facilitate different forms of personal and cultural renewal.

In sharing this pragmatist aesthetic frame, I propose that participatory drama has the potential to embody and reflect a poetics of personal and cultural renewal that exists within and around the drama workshop space. This has particular implications in a prison context, where the environment is fraught with tensions: it is a 'heterotopia' that is often ugly, dis-harmonious and an-aesthetic, and it invariably plays host to narratives of perverse and painful beauty, not just those harmonious stories of redemption and transformation. Renewal is a complex term that can accommodate the beautiful disturbance, disharmony and disorder in self- and world-creation, as much as its harmony and order. It can take shape over a whole lifespan, or in a single moment, or anywhere in between. A participatory drama process has the potential to privilege participants' versions of renewal, and these can be explored and articulated from within the process. The rehabilitative rhetoric in BWCC, like many prisons, focuses on remaking the women into successful law-abiding members of society who will not reoffend. This could be seen as the institutional ideal of renewal. But the concept of renewal should not become a handy replacement for rehabilitation, where the dynamic flow of aesthetic experience risks becoming dammed up into a stagnant pool of instrumentalism. A pragmatist aesthetic view inspired by the theorists I have named here is vibrant, dynamic and holistic - it seeks to unify affect and effect (Thompson 2009), rather than siphon the latter off in order to fulfil an instrumental agenda. By conceiving Deweyan and post-Deweyan aesthetics in concert with narrative theory, I have hopefully demonstrated how interventionist approaches to applied theatre and prison theatre can be theorized from within the art-form of drama. Dewey's aesthetic theory supports the notion that art should 'serve life' rather than 'prescribing a defined and limited mode of living' (1934: 140). By definition, pragmatist aesthetic theory integrates the instrumental with the aesthetic, and invites us to explore the dynamic tensions that exist within experience so that we can engage more fully with the art of living.

\section{REFERENCES}

Alexander, T.M. (1998), 'The art of life', in L.A. Hickman (ed.), Reading Dewey: Interpretations for a Postmodern Generation, Bloomington, IN: Indiana University Press, pp. 1-22.

Arnold, P.J. (2005), 'Somaesthetics, education and the art of dance', The Journal of Aesthetic Education, 39: 1, pp. 48-64.

Baim, C., Brookes, S. and Mountford, A. (2002) The Geese Theatre Handbook: Drama with Offenders and People at Risk, Winchester: Waterside Press.

Bottoms, S. (2010), 'Silent partners: Actor and audience in Geese Theatre's Journey Woman', Research in Drama Education: The Journal of Applied Theatre and Performance, 15: 4, pp. 477-96. 
Bruner, J.S. (1986), Actual Minds, Possible Worlds, Cambridge, MA: Harvard University Press.

- (1990), Acts of Meaning, Cambridge, MA: Harvard University Press.

Clandinin, D.J. and Connelly, F.M. (2000), Narrative Inquiry: Experience and Story in Qualitative Research, San Francisco: Jossey-Bass.

Dewey, J. (1934), Art as Experience, New York: Capricorn.

Easteal, P. (2001), 'Women in Australian prisons: The cycle of abuse and dysfunctional environments', The Prison Journal, 81: 1, pp. 87-112.

Foucault, M. (1986), 'Of other spaces', Diacritics, 16: 1, pp. 22-27.

- (1991), Discipline and Punish: The Birth of the Prison, Harmondsworth: Penguin.

Garrison, J. (1997), Dewey and Eros: Wisdom and Desire in the Art of Teaching, New York: Teachers College Press.

Granger, D.A. (2001), 'Towards an embodied poetics of the self: Personal renewal in Dewey and Cavell', Studies in Philosophy and Education, 20: 2, pp. 107-24.

- (2006), John Dewey, Robert Pirsig and the Art of Living: Revisioning Aesthetic Education, New York/Basingstoke: Palgrave Macmillan.

- (2010), 'Somaesthetics and racism: Toward an embodied pedagogy of difference,' The Journal of Aesthetic Education, 44: 3, pp. 69-81.

Haseman, B. and Winston, J. (2010), "Why be interested?" Aesthetics, applied theatre and drama education', Research in Drama Education: The Journal of Applied Theatre and Performance, 15: 4, 465-75.

Hughes, J. (2005), 'Doing the arts justice: A review of research literature, practice and theory', http://www.apcentre.org.uk. Accessed 9 February 2010.

Jewkes, Y. (2012), 'Aesthetics and an-aesthetics: The architecture of incarceration', in L.K. Cheliotis (ed.), The Arts of Imprisonment: Control, Resistance and Empowerment, Farnham: Ashgate, pp. 27-45.

Johnston, C. (1998), House of Games: Making Theatre from Everyday Life, London: Nick Hern.

Johnson, M. (2007), The Meaning of the Body: Aesthetics of Human Understanding, Chicago: University of Chicago Press.

Kershaw, B. (2004), 'Pathologies of hope in drama and theatre', in M. Balfour (ed.), Theatre in Prison: Theory and Practice, Bristol: Intellect, pp. 35-52.

Mackey, S. and Stuart Fisher, A. (2011), 'Introduction to Rustom Bharucha's Keynote Lecture: Problematising applied theatre: A search for alternative paradigms', Research in Drama Education: The Journal of Applied Theatre and Performance, 16: 3, pp. 365-84.

Maruna, S. (2001), Making Good: How Ex-Convicts Reform and Rebuild Their Lives, Washington, DC: American Psychological Association, Ovid Technologies Inc.

McAvinchey, C. (2011), Theatre and Prison, Basingstoke: Palgrave Macmillan.

Nicholson, H. (2005), Applied Drama: The Gift of Theatre, Basingstoke: Palgrave Macmillan.

O’Neill, C. (1995), Drama Worlds: Framework for Process Drama, Portsmouth: Heinemann.

Peterson, E.E. and Langellier, K.M. (2007), 'The performance turn in narrative studies', in M. Bamburg (ed.), Narrative - State of the Art, Amsterdam: John Benjamins.

Prendergast, M. (2011), 'Utopian Performatives and the Social Imaginary: Toward a New Philosophy of Drama/Theater Education', The Journal of Aesthetic Education, 45: 1, pp. 58-73. 
Prendergast, M. and Saxton, J. (eds) (2009), Applied Theatre: International Case Studies and Challenges for Practice, Bristol: Intellect.

Rasmussen, B. and Gürgens, R. (2006), 'Art as part of everyday life: Understanding applied theatre practices through the aesthetics of John Dewey and Hans Georg Gadamer', Theatre Research International, 31: 3, pp. $235-44$.

Rasmussen, B. (2010), "The "good enough" drama: Reinterpreting constructivist aesthetics and epistemology in drama education', Research in Drama Education: The Journal of Applied Theatre and Performance, 15: 4, pp. 529-46.

Ricoeur, P. (1984), Time and Narrative, Chicago: University of Chicago Press.

Sarbin, T.R. (1997), 'The Poetics of Identity', Theory and Psychology, 7: 1, pp. 67-82.

- (1998), 'The poetic construction of reality and other explanatory categories', in J. De Rivera and T.R. Sarbin (eds), Believed-in Imaginings: The Narrative Construction of Reality, Washington, DC: American Psychological Association.

- (2005), 'If these walls could talk: Places as stages for human drama', Journal of Constructivist Psychology, 18: 3, pp. 203-14.

Shusterman, R. (2000), Pragmatist Aesthetics: Living Beauty, Rethinking Art, Lanham, MD: Rowman and Littlefield.

(2008), Body Consciousness: A Philosophy of Mindfulness and Somaesthetics, New York: Cambridge University Press.

_ (2011), 'Soma, self and society: Somaesthetics as pragmatist meliorism', Metaphilosophy, 42: 3, 314-27.

Stoller, A. (2013), 'Educating from failure: Dewey's aesthetics and the case for failure in educational theory', The Journal of Aesthetic Education, 47: 1, pp. 22-35.

Taylor, P. and Warner, C.D. (2006), Structure and Spontaneity: The Process Drama of Cecily O'Neill, Stoke on Trent: Trentham.

Thompson, J. (2009), Performance Affects: Applied Theatre and the End of Effect, Basingstoke: Palgrave Macmillan.

Turner, V. (1981), 'Social dramas and stories about them, in W.T.J. Mitchell (ed.), On Narrative, Chicago: University of Chicago Press, pp. 209-32.

Walsh, A. (2014), '(En)gendering habitus: Women, prison, resistance', Contemporary Theatre Review, 24: 1, pp. 40-52.

White, G. (ed.) (2015), Applied Theatre: Aesthetics, London/New York: Bloomsbury.

Winston J. (2010), Beauty and Education: New York/Abingdon: Routledge.

\section{SUGGESTED CITATION}

Woodland, S. (2016), 'The art of living in prison: A pragmatist aesthetic approach to participatory drama with women prisoners', Applied Theatre Research, 4: 3, pp. 223-36, doi: 10.1386/atr.4.3.223_1

\section{CONTRIBUTOR DETAILS}

Sarah Woodland is a practitioner, researcher and educator in applied theatre, with a particular focus on practice-led research and prison theatre. Sarah has an interest in performance that draws on personal narrative, such as reminiscence and testimonial theatre, and is developing participatory approaches to radio drama. She has used these approaches in many different settings over 
the past 20 years, completing a Ph.D. at Griffith University in 2015. Sarah teaches undergraduate courses in applied theatre, works as a research fellow in the Queensland Conservatorium Research Centre and is a research fellow (Adjunct) with the Griffith Institute for Educational Research.

Contact: Griffith Institute for Educational Research (GIER), Griffith University, Mt Gravatt QLD 4122, Australia.

Email: s.woodland@griffith.edu.au

Sarah Woodland has asserted her right under the Copyright, Designs and Patents Act, 1988, to be identified as the author of this work in the format that was submitted to Intellect Ltd. 